\title{
Correlating the morphology of poly(L-lactide)/poly(butylene succinate)/graphene oxide blends nanocomposites with their crystallization behavior
}

\author{
S. E. Fenni ${ }^{1,2}$, O. Monticelli ${ }^{2}$, L. Conzatti ${ }^{3}$, R. Doufnoune ${ }^{4}$, P. Stagnaro $^{3}$, N. Haddaoui $^{1 *}$, \\ D. Cavallo ${ }^{2}$ \\ ${ }^{1}$ Laboratoire de Physico-Chimie des Hauts Polymères (LPCHP), Département de Génie des Procédés, Faculté de \\ Technologie, Université Ferhat ABBAS Sétif-1, 19000 Setif, Algeria \\ ${ }^{2}$ Department of Chemistry and Industrial Chemistry, University of Genova, via Dodecaneso 31, 16146 Genova, Italy \\ ${ }^{3}$ Institute for Macromolecular Studies (ISMac), CNR, Via De Marini 6, 16149 Genova, Italy \\ ${ }^{4}$ Unité de Recherche sur les Matériaux Emergents -Sétif- URMES, Equipe de Valorisation des Matériaux Polymériques, \\ Université Ferhat Abbas Sétif-1, 19000 Setif, Algeria
}

Received 7 July 2017; accepted in revised form 2 September 2017

\begin{abstract}
Bio-based blend nanocomposites of poly(L-lactic acid) (PLLA) and poly(butylene succinate) (PBS), with different concentrations (from 0.1 to $0.5 \mathrm{wt} \%$ ) of graphene oxide (GO), are prepared via solution dispersion of PBS/GO followed by melt blending with PLLA in a 70/30 PLLA/PBS weight ratio. Scanning and Transmission Electron Microscopy reveals micron-sized droplets of PBS in the PLLA matrix with the GO nanofiller preferentially found in the PBS phase. The GO acts as nucleating agent for both semicrystalline polymers. The nanofiller nucleating effect is compared to the one of own selfnuclei for each polymer, to define a convenient nucleating efficiency (NE) scale. A value of around $80 \%$ is determined for GO towards PBS, among the highest NEs ever reported for this polymer. On the other hand, the efficiency in nucleating PLLA is equal to a modest $15 \%$, also due to the uneven distribution of the nanofiller in the two polymers. A close relationship between the nanocomposite morphology and crystallization behavior of the two different polymers is thus established.
\end{abstract}

Keywords: nanocomposites, graphene oxide, polylactic acid, poly(butylene succinate)

\section{Introduction}

Poly(L-lactic acid) (PLLA) is an excellent environmental friendly plastic [1,2], due to its high rigidity, biocompatibility and biodegradability [3, 4]. However, the high costs, the brittleness and slow crystallization kinetics of PLLA limit its application as a commodity polymer [5]. Consequently, modification of the polymer to achieve suitable properties has been a major research effort during the last decade [3, 6, 7]. Various additives, such as toughening agents, plasticizers, nucleating agents and reinforcing fillers have been incorporated into PLLA matrix. In addition, modification of PLLA by melt blending with other polymers is also a useful way to overcome the previously mentioned drawbacks $[3,4]$.

Blending of polymers is an effective way to achieve an attractive combination of polymer properties [8], usually absent in the pure components. However, given that most polymer pairs are thermodynamically immiscible, often the final blends are fragile or with poor mechanical properties $[1,2]$. Several strategies for improving the compatibility between the different components of the blend have been developed $[9,10]$. These traditionally include polymer surface

"Corresponding author, e-mail: n_ haddaoui@yahoo.com (C) BME-PT 
modification by chemical reactions, and the incorporation of block-copolymers [2]. More recently, the compatibilizing role of nanoparticles has been explored for nano-clay [2], titanium dioxide $\left(\mathrm{TiO}_{2}\right)$ [11], zinc oxide $(\mathrm{ZnO})$, silica $\left(\mathrm{SiO}_{2}\right)$, aluminium oxide $\left(\mathrm{Al}_{2} \mathrm{O}_{3}\right)$, silicon nitride $\left(\mathrm{Si}_{3} \mathrm{~N}_{4}\right)[4,12]$, polyhedral oligomeric silsesquioxanes (POSS) [13], graphene oxide (GO), etc. $[14,15]$. It is often observed that these nanoparticles can concentrate at the interface between the two polymers, lowering the effective surface tension and thus enhancing the interaction between the two polymer phases [16-19].

Blends of PLLA with other bio-degradable polymers have been widely studied. For example, different flexible polymers, such as poly(hydroxybutyrate) (PHB), poly( $\varepsilon$-caprolactone) (PCL), poly(ethylene glycol) (PEG), and poly(butylene succinate) (PBS), have been used to toughen PLLA. In the present work we focused on PLLA/PBS blends, given the biodegradability and good processability of PBS [12, 20-25].

A variety of compounds has been added to blends of these two polymers, with the aim of improving their physical properties. Chen et al. [2] found that a reactive organoclay with glycidyl functionality acts as a compatibilizer for PLLA/PBS blends, improving the elongation at break and tensile modulus [4]. Homklin et al. [8] clarified the effect of nucleating agents on the PLLA/PBS blend properties: adding nano-sized calcium carbonate or sodium benzoate improved mechanical properties, processability, and productivity in mold processing of the blend [26]. Yokohara et al. [4] reported that cellulose nanocrystals improved the barrier properties and increased the Young modulus of the blend. Buasri et al. [11] studied the effect of $\mathrm{TiO}_{2}$ nanoparticles finding an enhancement of physical, mechanical and thermal behavior of the blend.

Recently, graphene oxide has been investigated as nano-compatibilizer and nano-reinforcement in polymer blends [14, 15, 27, 28]. Cao et al. [15] found that the addition of only $0.5 \mathrm{wt} \%$ of GO to the immiscible polyamide/poly(phenylene oxide) (PA/PPO) blend reduces the interfacial tension between the components, thanks to the amphiphilic nature of the graphene oxide. As such, the droplet size of the PPO minor phase decreases, thus improving the ductility and mechanical strength of the blend. Yang et al. [14] obtained similar results for nylon-6/poly(vinylidene fluoride) (PVDF) blends. Moreover, graphene oxide has also revealed a good nucleating ability towards several semi-crystalline polymers, including for instance isotactic polypropylene (iPP) [29-31], PVDF [32-34], PCL [35], and the two polymers object of the present study, PLLA and PBS [36, 37]. As such, in the current work the dual role of GO added in low amounts to PLLA/PBS blend is investigated. For a given phase composition of the blend (PLLA/PBS 70/30 wt\%), different concentrations of $\mathrm{GO}(0.1$ to $0.5 \mathrm{wt} \%)$ were introduced via melt-blending. Subsequently the polymer blend/GO nanocomposites were submitted to detailed characterization of their morphology and crystallization behaviour, focusing in particular on the compatibilizing and nucleating effect of the graphene oxide additive.

\section{Materials and methods}

\subsection{Materials}

Poly(L-lactic acid) (PLLA) (Synterra 1010) was supplied by Synbra Technology (Etten-Leur, Netherlands). PLLA 1010 is a crystallizable grade of PLLA with a L-lactide content of about $99 \mathrm{wt} \%$. The melting point is in the range $175-180^{\circ} \mathrm{C}$ and the glass transition temperature $\left(T_{\mathrm{g}}\right)$ is located about $55-60^{\circ} \mathrm{C}$. The polymer shows a melt flow rate (MFR) of about $12 \mathrm{~g} / 10 \mathrm{~min}\left(190^{\circ} \mathrm{C}, 2.16 \mathrm{~kg}\right.$, ISO 1133) and a density of $1.25 \mathrm{~g} / \mathrm{cm}^{3}$.

Poly(butylene succinate) (PBS) (PBI 003) was supplied by Natureplast (Caen, France). PBS (PBI 003) is a crystallizable polymer with a melting point in the range $110-115^{\circ} \mathrm{C}$ and a $T_{\mathrm{g}}$ of ca. $-35^{\circ} \mathrm{C}$. The MFR is about $15-25 \mathrm{~g} / 10 \min \left(190^{\circ} \mathrm{C}, 2.16 \mathrm{~kg}\right.$, ISO 1133) and its density is $1.26 \mathrm{~g} / \mathrm{cm}^{3}$.

Graphene Oxide (GO) (796034) was purchased from Sigma-Aldrich. It consists of a powder of GO nanosheets (approximately15-20 sheets) with a degree of edge-oxidation of 4-10\%. Acetone and anhydrous $N, N$-Dimethylformamide (DMF) $(99.8 \%$ pure) were supplied by Sigma-Aldrich and used as received.

\subsection{Preparation of $\mathrm{PBS} / \mathrm{GO}$ masterbatches}

PBS/GO masterbatches were prepared through a solution-mixing method, previously adopted for the preparation of $\mathrm{PA} / \mathrm{PPO} / \mathrm{GO}$ and nylon 6/PVDF/GO blend nanocomposites. At first, a suspension of GO in DMF was obtained by sonicating the mixture at $80^{\circ} \mathrm{C}$ for $1 \mathrm{~h}$, in order to partially exfoliate the GOs into single-layer sheets $[14,15,38]$. The concentration of GO in the suspension was $1 \mathrm{mg} / \mathrm{mL}$. Concomitantly, $15 \mathrm{~g}$ of PBS were dissolved in $50 \mathrm{~mL}$ of DMF, by stirring at $100^{\circ} \mathrm{C}$ for $1 \mathrm{~h}$. Subsequently, the GO suspension in DMF was added to the PBS solution 
and continuously stirred at $100^{\circ} \mathrm{C}$ for $10 \mathrm{~min}$. Different amounts of suspension $(50,150$ and $250 \mathrm{~mL})$ were used, in order to obtain a final concentration in the blend of $0.1,0.3$ and $0.5 \mathrm{wt} \%$. The mixture was finally precipitated and coagulated by the addition of $400 \mathrm{~mL}$ of acetone. The precipitate was washed four times with acetone, filtered under vacuum overnight, and then dried at $60^{\circ} \mathrm{C}$ for $24 \mathrm{~h}$, yielding PBS/GO masterbatches with the desired GO concentration [14, 15].

\subsection{Preparation of GO-compatibilized PLLA/PBS blend nanocomposites}

Before melt blending, the PLLA and PBS/GO masterbatches were dried at $60^{\circ} \mathrm{C}$ for $48 \mathrm{~h}$. The PBS/GO masterbatches were melt blended with PLLA in different ratios, to obtain the following PLLA/PBS/GO compositions (70/30, 70/30/0.1, 70/30/0.3, 70/30/0.5 by weight). The melt blending was accomplished in a Plastograph Brabender internal mixer (W50 EHT, Brabender $\mathrm{GmbH}$, Germany), at a temperature of $180^{\circ} \mathrm{C}$ with rotor speed of $60 \mathrm{rpm}$ for $10 \mathrm{~min}$, under continuous nitrogen flow.

\subsection{Characterization}

\subsubsection{Field-emission scanning electron microscopy: (FE-SEM)}

The morphology of the fractured surface of blend nanocomposites was investigated using a Field-emission scanning electron microscope (Supra $40 \mathrm{VP}$ model, Zeiss, Germany) at an accelerating voltage of $1 \mathrm{kV}$. The specimens were submerged in liquid nitrogen for $30 \mathrm{~min}$ and fractured cryogenically. All samples were thinly sputter-coated with carbon using a Polaron E5100 sputter coater.

\subsubsection{Transmission electron microscopy (TEM)}

TEM analysis was performed by using a EM 900 microscope (Zeiss, Germany) operating at an accelerating voltage of $80 \mathrm{kV}$. Ultrathin sections (about $50 \mathrm{~nm}$ thick) were obtained using a EM FCS cryoultramicrotome (Leica Microsystems GmbH, Germany) equipped with a diamond knife. The sample was kept frozen at $-80^{\circ} \mathrm{C}$ during sectioning.

\subsubsection{Thermal analyses with differential scanning calorimetry (DSC)}

DSC was performed using a DSC1 STARe System (Mettler-Toledo, Switzerland). Several temperature protocols were employed in order to investigate in details the crystallization behavior of the PLLA/PBS blend and its nanocomposites with GO. During the DSC runs, a nitrogen flow at a rate of $20 \mathrm{~mL} / \mathrm{min}$ was constantly applied.

\section{Non isothermal crystallization}

The samples were molten at $200^{\circ} \mathrm{C}$ for $3 \mathrm{~min}$ and then cooled to $-50^{\circ} \mathrm{C}$ at a rate of $10^{\circ} \mathrm{C} / \mathrm{min}$. After cooling, the polymer was subsequently heated to $200^{\circ} \mathrm{C}$ at $10^{\circ} \mathrm{C} / \mathrm{min}$.

\section{Isothermal crystallization of neat $P B S$}

The polymer was molten at $160^{\circ} \mathrm{C}$ for $3 \mathrm{~min}$ and subsequently cooled to the chosen isothermal crystallization temperature at $20^{\circ} \mathrm{C} / \mathrm{min}$ and kept at the isothermal crystallization temperature for the required time. The isothermal temperatures were in the range $88-96^{\circ} \mathrm{C}$.

\section{Isothermal crystallization of PBS in blends}

The minor component of the blend was crystallized isothermally after the crystallization of the PLLA matrix. To this aim, after the first non-isothermal run (see above), the sample was heated to $160^{\circ} \mathrm{C}$ at $10^{\circ} \mathrm{C} / \mathrm{min}$. This temperature is below the PLLA phase melting point, but high enough to completely melt the PBS domains. After $3 \mathrm{~min}$ at $160^{\circ} \mathrm{C}$ the blend sample was cooled to the chosen isothermal crystallization temperature, in the range $98-105^{\circ} \mathrm{C}$ ), at a rate of $20^{\circ} \mathrm{C} / \mathrm{min}$, and kept there for an adequate time.

\section{Isothermal crystallization of PLLA}

The PLLA component was molten at $200^{\circ} \mathrm{C}$ for $3 \mathrm{~min}$ and then cooled to the chosen isothermal crystallization temperature (in the range $115-140^{\circ} \mathrm{C}$ ) at a rate of $20^{\circ} \mathrm{C} / \mathrm{min}$, and kept there for the required time.

\section{Results and discussion}

\subsection{Morphological characterization}

The morphology of neat PLLA/PBS blend and PLLA/PBS/GO blend nanocomposites was firstly observed by FE-SEM. Figure 1 reports the FE-SEM images of the fragile fracture surfaces of the neat PLLA/PBS blend (Figure 1a, 1d) compared with those of the nanocomposites containing 0.3 and $0.5 \mathrm{wt} \%$ GO (Figure 1b, 1e and 1c, $1 \mathrm{f}$ respectively). PLLA/PBS blends are known to be immiscible, with the two phases forming clearly separated domains $[4,6]$. As such, the composition used in this study resulted in a typical sea-island morphology, in which PLLA constitutes the continuous matrix and the PBS 
minor phase is dispersed into spherical domains with an average diameter in the range of $1-2 \mu \mathrm{m}$ (Figure 1). Slightly larger PBS domains are found in the blend nanocomposites, i.e., the size increases from around $1 \mu \mathrm{m}$ in the neat PLLA/PBS blend to above $2 \mu \mathrm{m}$ in PLLA/ PBS blend containing $0.5 \mathrm{wt} \% \mathrm{GO}$. The fracture surface of the neat PLLA/PBS blend (Figure 1a, 1d) shows a clear detachment of the PBS

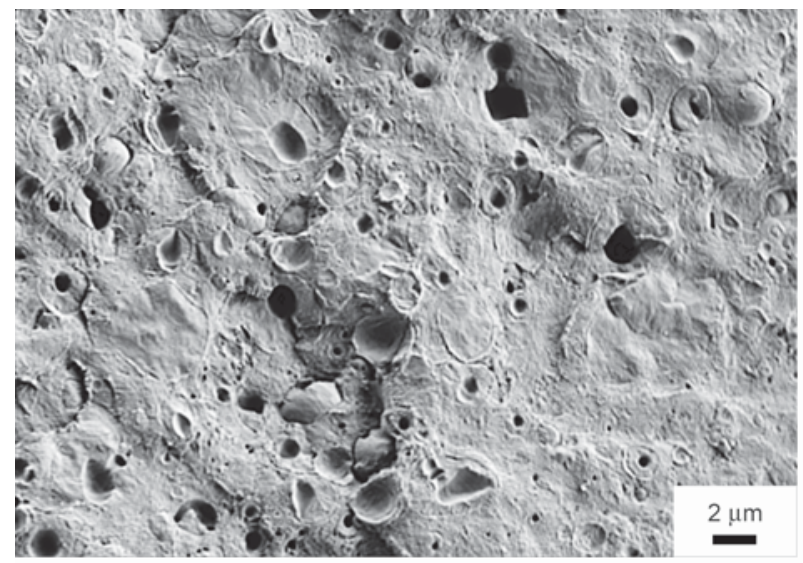

$$
\text { a) }
$$

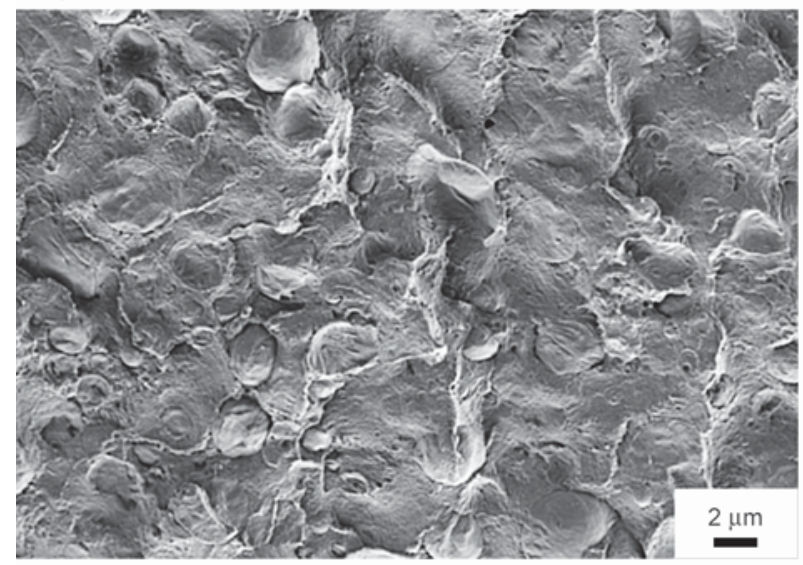

b)

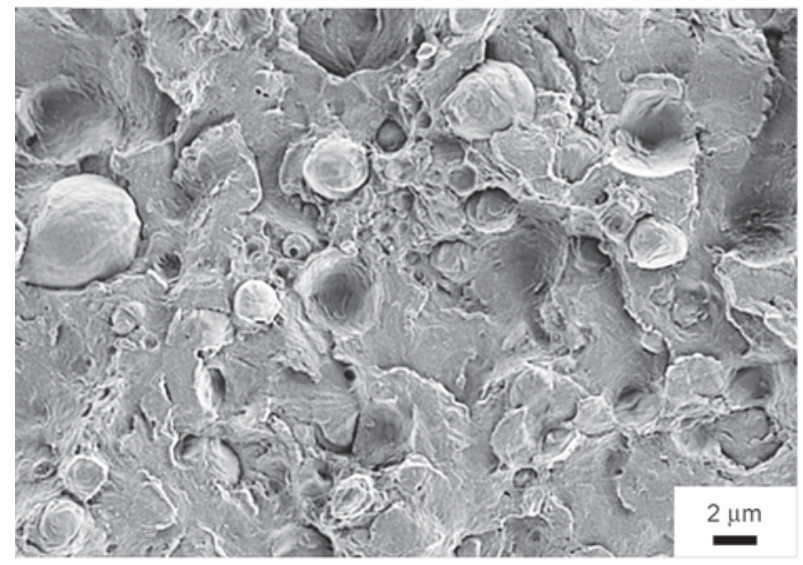

phase from the PLLA matrix: voids with a neat and smooth demarcation surface are in fact observed throughout the sample.

On the other hand, the morphology of fractured PLLA/PBS/GO blends nanocomposites (Figure 1b1e, 1c-1f) evidenced an improved adhesion between the two polymers. Indeed, when GO is present: i) a considerably lower number of voids left by detached

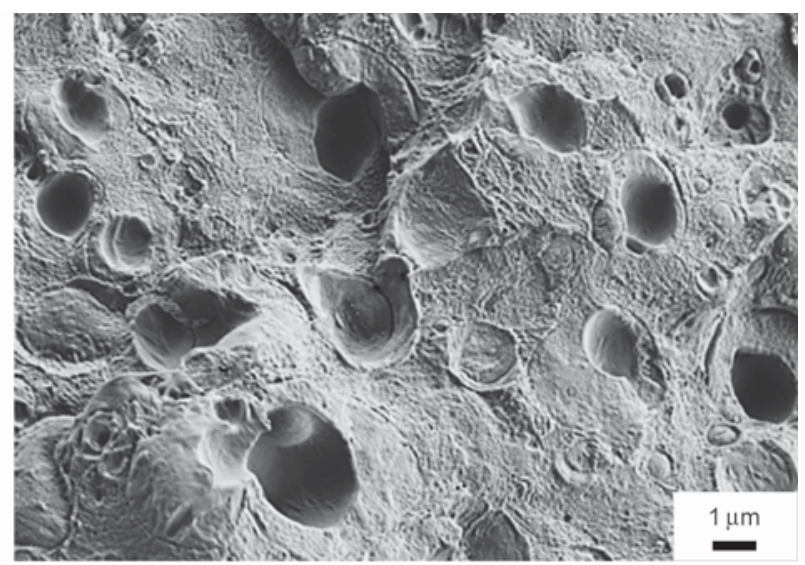

d)

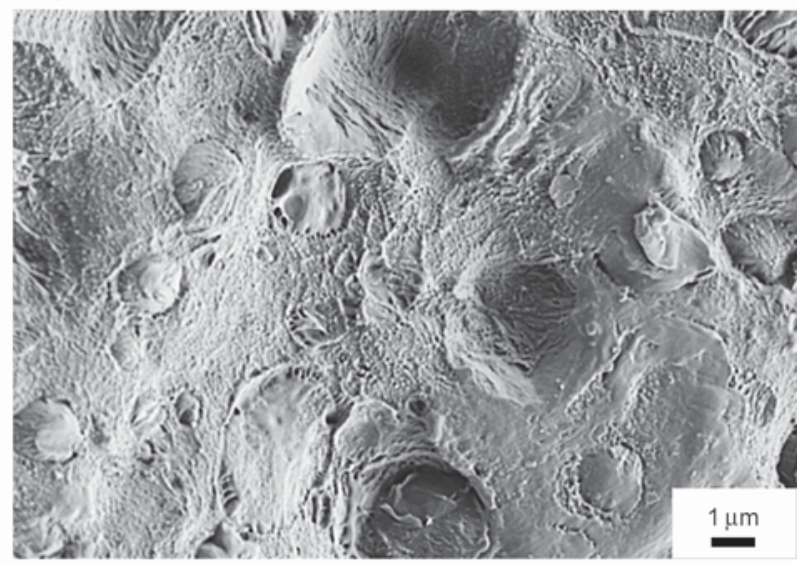

e)

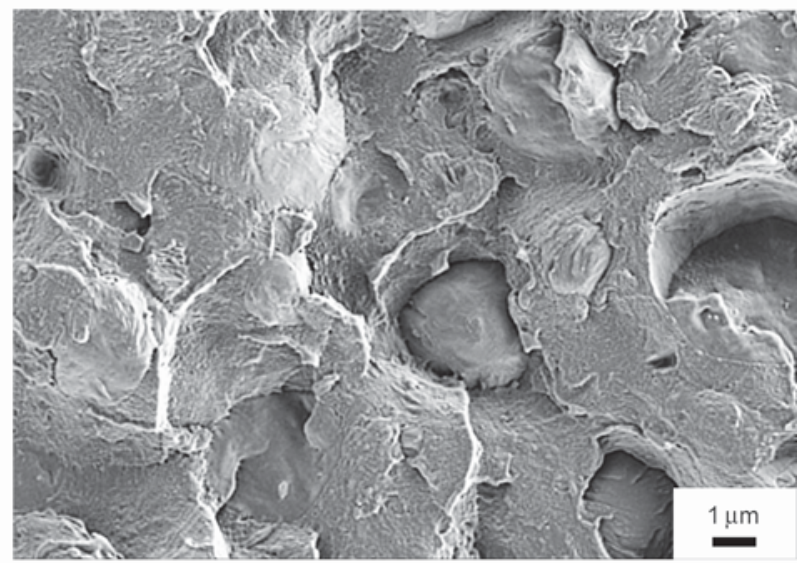

f)

Figure 1. FE-SEM images of the PLLA/PBS/GO blend nanocomposites with different concentration of graphene oxide and at different magnifications ((a), (b) and (c) 10000×; (d), (e) and (f) 20000×). (a) and (d) (70/30/neat), (b) and (e) $(70 / 30 / 0.3 \mathrm{wt} \% \mathrm{GO}),(\mathrm{c})$ and (f) $(70 / 30 / 0.5 \mathrm{wt} \%)$. 
PBS droplets is observed; ii) an irregular surface appears in the cavities left by the detachment of the PBS domains. This fracture morphology is analogous to compatibilized immiscible polymer blends with or without graphene oxide $[5,15]$. Moreover, fibrillar structures localized at the interfaces between the two polymers are occasionally found (see Figure 1e, 1f). Although the origin of this morphological entities is not clear, similar results were reported by Ye et al. [27] by adding GO to PMMA/PS blends. The observed morphological features indicate a higher interaction between PBS and PLLA, which

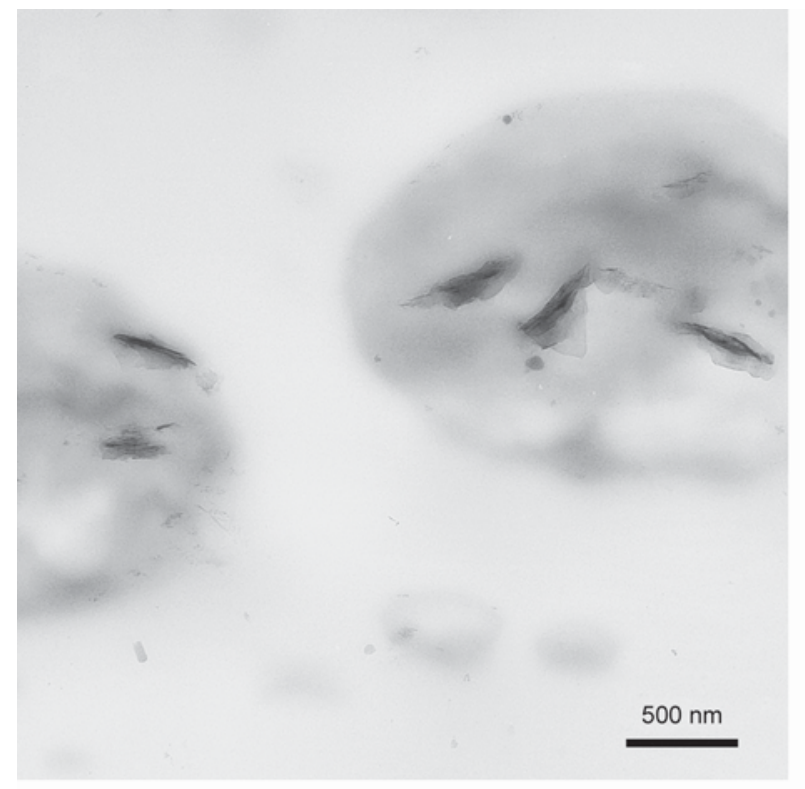

a)

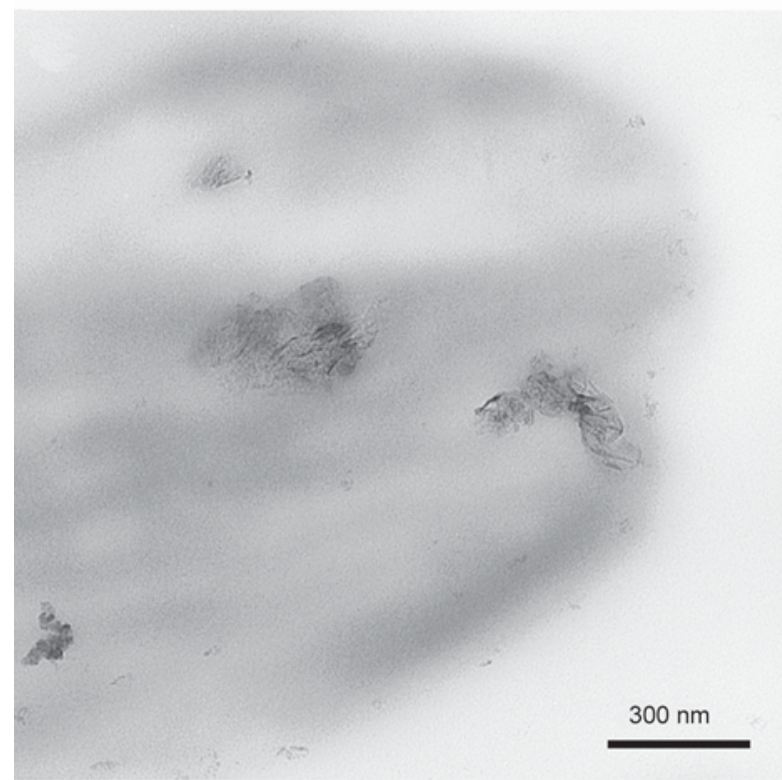

c) could be induced by GO nanosheets located, at least in part, at the interface between the two polymers. In order to investigate this hypothesis, TEM analysis of the blends nanocomposites has been performed; and some representative micrographs for PLLA/PBS/ GO with 0.3 and $0.5 \mathrm{wt} \% \mathrm{GO}$ additive are shown in Figure 2 . The two different polyesters can be easily distinguished because of their difference in electron density that lead to sufficient contrast in the TEM image. The PBS domains appear darker than the PLLA matrix, with round/ellipsoidal shape and average sizes around 1-2 $\mu \mathrm{m}$, in perfect agreement with

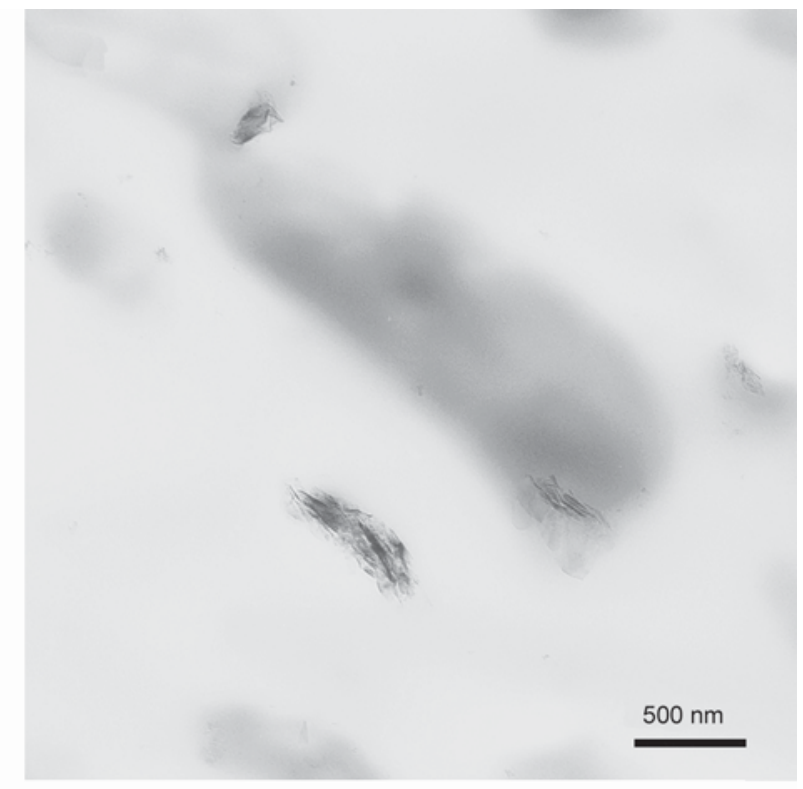

b)

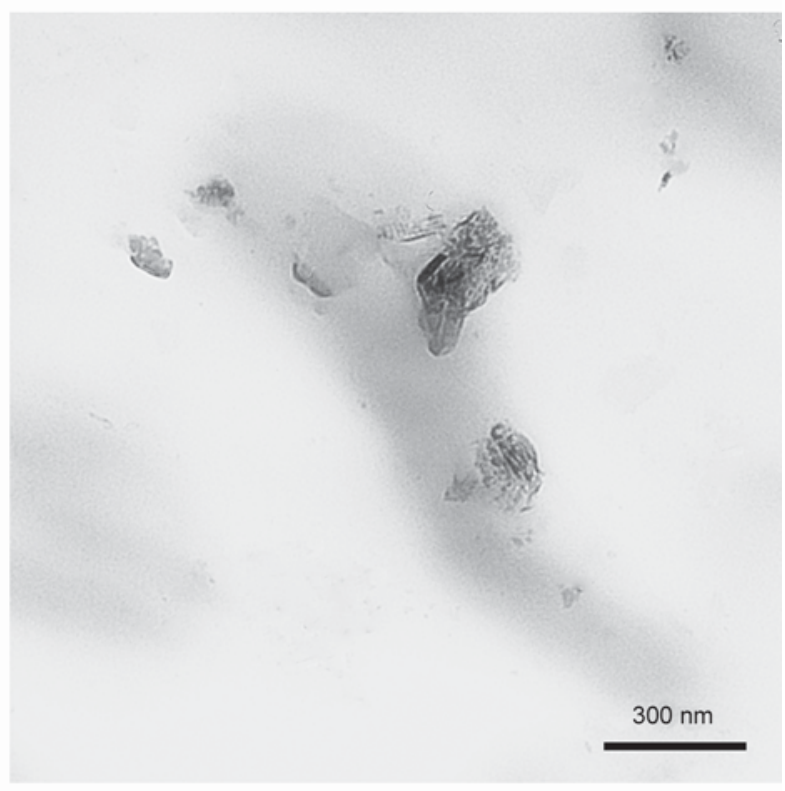

d)

Figure 2. TEM micrographs at different magnifications of the PLLA/PBS/GO blend nanocomposites with different concentration of graphene oxide: 70/30/0.3 wt\% GO (a, c), and 70/30/0.5 wt\% GO (b, d) 
the morphology disclosed by FE-SEM of fracture surfaces. Small stacks or aggregates of GO nanosheets can be easily recognized. The large majority of GO is located within the PBS phase, although occasionally some GO stacks are also found in the PLLA matrix. Figure 2 demonstrates that the dispersion of GO nanosheets is generally good, since also some isolated sheets are observed, together with the aggregate. Moreover the extent of aggregation is minimal, since the observed lateral size of these aggregates is well below the micron: few hundreds nanometers, at most. The lower grey intensity of some areas of the aggregates indicates a lower number of GO nanosheets crossed by the electron beam, suggesting a good extent of exfoliation during the composite preparation. Although the TEM micrographs show that several GO nanosheets are located close to the phase boundary between the two immiscible polymers, an evident adsorption of the nanofiller at the interface could not be observed. Given that the TEM micrographs are a 2-D projection of the real 3-D bulk material, the possibility that GO stacks might in reality be at the boundaries between the two polymer phases at a different height of the PBS droplet, i.e., at the upper or lower interfaces, cannot be ruled out. The enhanced adhesion between PLLA and PBS demonstrated with the FE-SEM could thus be due also to different reasons, such as the development of a transcrystalline layer at the polymer-polymer contact line, or to a GO catalyzed transesterification in the melt.

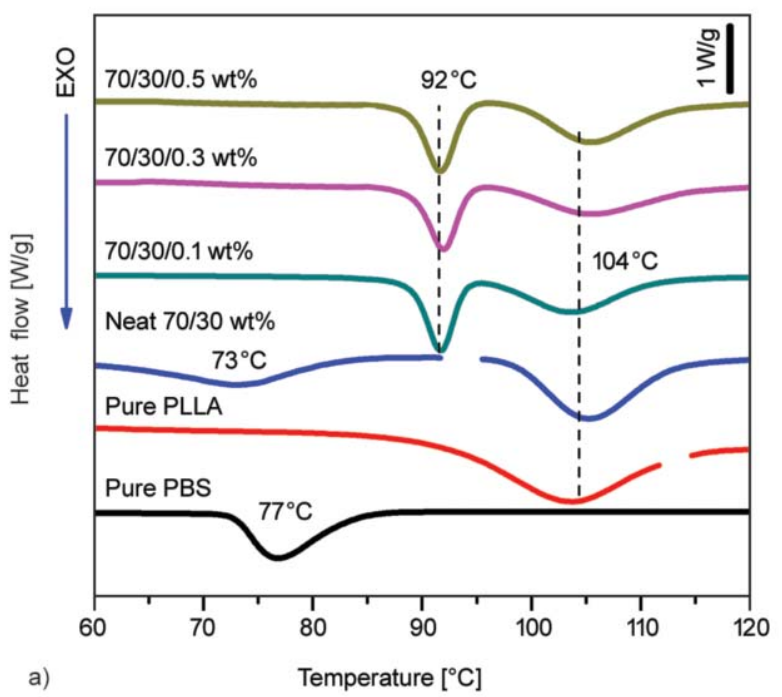

\subsection{Crystallization of PLLA/PBS/GO blend nanocomposites}

The non-isothermal crystallization of the PLLA/PBS blend and nanocomposites with GO is investigated by differential scanning calorimetry, and the main results are reported in Figure 3. The investigated system being a double-crystalline polymer blend, it is possible to evaluate the effect of the nanofiller on the crystallization behavior of both polyesters.

At first, the crystallization behavior of the two components and of the neat PLLA/PBS (70/30) blend can be considered. PBS shows a crystallization exotherm around $77^{\circ} \mathrm{C}$ on cooling at $10^{\circ} \mathrm{C} / \mathrm{min}$, and the subsequent melting reveal a cold-crystallization of one of the polymers, followed by a broad melting characterized by re-crystallization phenomena. Pure PLLA partially crystallizes on cooling slightly above $100^{\circ} \mathrm{C}$, and the crystallization process is completed during the heating scan. Just before melting the PLLA crystals, a slight exothermic event is observed, tentatively attributed to the reorganization of a disordered modification into the more stable $\alpha$ form $[39,40]$. Upon mixing the two polymers in a 70:30 PLLA/PBS weight ratio, the crystallization process is affected, while the melting curve is practically unaltered with respect to a combination of those of the pure components (Figure 3b). When the PBS is the minor dispersed phase in the blend with PLLA, its crystallization temperature is decreased of about $5{ }^{\circ} \mathrm{C}$ with respect to pure PBS (Figure 3a). This effect is known to occur in immiscible blends:

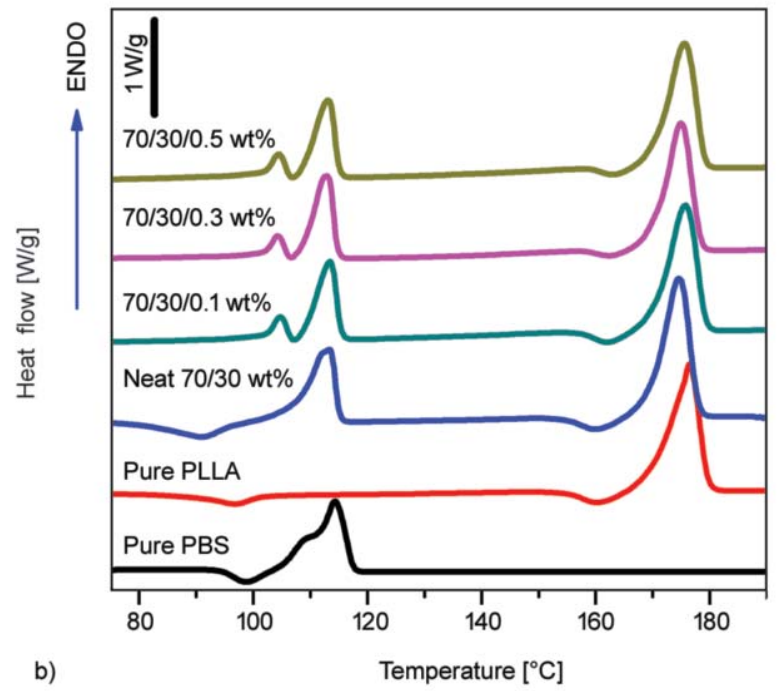

Figure 3. Cooling (a) and subsequent heating (b) DSC curves of the different PLLA/PBS/GO blend nanocomposites with various content of GO, compared to the PLLA/PBS (70/30) neat blend and the two pure polymers (scaled for their weight fraction in the blend) 
if the domain size of the minor component is small enough, fractionated crystallization can be observed, since most of the PBS droplets will be free of nucleating heterogeneities, and their crystallization takes place at higher undercooling. [41]. On the other hand, the crystallization of the PLLA component in the neat blend is slightly enhanced. This indicates a weak nucleating activity of the PBS/PLLA interfaces. Although limited, this nucleating effect is rather interesting, because PBS droplets are still in the molten state, when the nucleation of the PLLA matrix on their surfaces occurs. Similar results have been previously reported, both for melt and cold-crystallization of PLLA in blends with PBS. [4, 42]. The occurrence of this nucleation might be due to a low surface tension existing between PLLA lateral crystal surfaces and PBS melt. Nucleation at the interfaces between immiscible polymer components, during or after phase separation, has been predicted theoretically [43] and observed experimentally also in amorphous/semicrystalline polymer pairs [44].

The addition of relatively small quantities of graphene oxide has a large impact on the crystallization behavior of PLLA/PBS (70/30 wt \%) blend. In particular, the crystallization temperature of the PBS dispersed phase in the nanocomposites shows a remarkable increase of about $20^{\circ} \mathrm{C}$ with respect to the one in the neat blend. The nucleating effect of GO on PBS is already observed at the lower loading of nanofiller, and practically does not depend on GO concentration. The measured change in crystallization temperature is remarkable, in comparison to previous literature results, where only a mild nucleation effect is observed, when a similar concentration of GO is added to PBS $[37,45,46]$. The difference with literature results can be attributed to a different degree of dispersion of the nanofiller, obtained thanks to the solution-assisted nanocomposite preparation method. Indeed, the TEM micrographs shown in Figure 2 demonstrate that the GO particles are partially exfoliated and the extent of aggregation is minor, as only aggregates with size of few hundreds nanometers are found. On the other hand, GO have only a small accelerating effect on PLLA crystallization, especially at the highest nanofiller concentrations. This result is in agreement with previous literature on PLLA/GO composites, which documented a limited nucleating effect of the nanofiller on polylactide. [47-49] Moreover, this modest effect observed in the PLLA/PBS blend nanocomposites could be ascribed to the particular morphology of the system. The GO might not efficiently be transferred from the PBS/GO masterbatch to the bulk of PLLA phase during the mixing stage. In fact, TEM results reported in Figure 2, indicate that graphene oxide are most frequently found inside the PBS domains. As such, nucleation of PLLA by the action of GO can occur mainly at the PBS/PLLA interfaces, or thanks to the few that moved to the bulk of PLLA matrix form the PBS droplets. The role of GO as heterogeneous nucleants for both crystalline polymers would be further explored in the following, with self-nucleation and isothermal crystallization experiments. We note that the melting behavior of PLLA/PBS blends (Figure $3 \mathrm{~b}$ ) is not significantly affected by the addition of graphene oxide. The only meaningful effect is the appearance of a more marked melting-recrystallization behavior of PBS, with evident double melting peaks for all the employed GO concentrations. The double melting peaks of PBS is widely discussed in the literature, and commonly interpreted as a melting-recrystallization phenomenon. Its occurrence in the present blend nanocomposite is related to the increase in the PBS phase crystallization temperature [50-53].

The relevant nucleating ability of GO on the PBS phase can be quantitatively described, by using the nucleation efficiently scale concept introduced by Lotz et al. [54] in order to define a scale of nucleation efficiency, two reference values corresponding to a minimum and maximum in the crystallization rate should be chosen. When non-isothermal crystallization is considered, the minimum value obviously corresponds to the crystallization temperature of the neat, non-nucleated polymer. The maximum value is calculated by performing self-nucleation experiments. The polymer is submitted to a melting procedure at decreasing temperatures, until some crystalline seeds remain in the molten material and act as 'self-nuclei' upon re-crystallization. The detailed procedure is described elsewhere. Self-nucleation allows obtaining a relevant increase of the crystallization temperature, typically of $20^{\circ} \mathrm{C}$ or more. The crystallization temperature of the polymer at the 'optimal' self-nucleation temperature is taken as the $100 \%$ value of the nucleating efficiency scale. Any given nucleating agent can thus be quantitatively evaluated, by comparing the crystallization temperature increase of the nucleated sample with that provoked by self-nucleation. 
The nucleating efficiency of various nucleants in different semicrystalline polymer matrices, rarely exceeds $60 \%$ [55-58], although exceptional cases of 'supernucleation' (with nucleating efficiency above $100 \%$ ) are reported in specially prepared polymer/ carbon nanotubes composites [59]. In Figure 4a, the crystallization temperature of the PBS phase in PLLA/PBS 70/30 neat blend at different self-nucleation (SN) temperatures is compared with that of PLLA/PBS/GO blend nanocomposite (with $0.5 \mathrm{wt} \%$ $\mathrm{GO})$. Note that the values for the non-self-nucleated blend and for the nanocomposite have actually been obtained by cooling from the melt at $200^{\circ} \mathrm{C}$, but they are reported at an arbitrary SN temperature, for the sake of comparison. The PBS crystallization temperature remain constant and substantially equal to the one characteristic of non-self-nucleated melts (i.e. cooled from $200^{\circ} \mathrm{C}$ ) for melt annealing temperatures between 160 and $130^{\circ} \mathrm{C}$. Decreasing the self-nucleation temperature from $130^{\circ} \mathrm{C}$ to about $115^{\circ} \mathrm{C}$ results in a large increase of the PBS phase crystallization temperatures, of approximately $25^{\circ} \mathrm{C}$. The crystallization temperature corresponding to a $100 \%$ nucleating efficiency value is thus about $97^{\circ} \mathrm{C}$. The one obtained in PLLA/PBS/GO nanocomposites, independently of the $\mathrm{GO}$ concentration is $92^{\circ} \mathrm{C}$, resulting in a relative efficiency slightly higher than $80 \%$. This value of nucleating efficiency, which is reached already at a concentration of $0.1 \mathrm{wt} \%$, is surely among the highest ever reported in the literature for an additive which is dispersed in the polymer via common solution/melt routes. It should be noted that in nu-

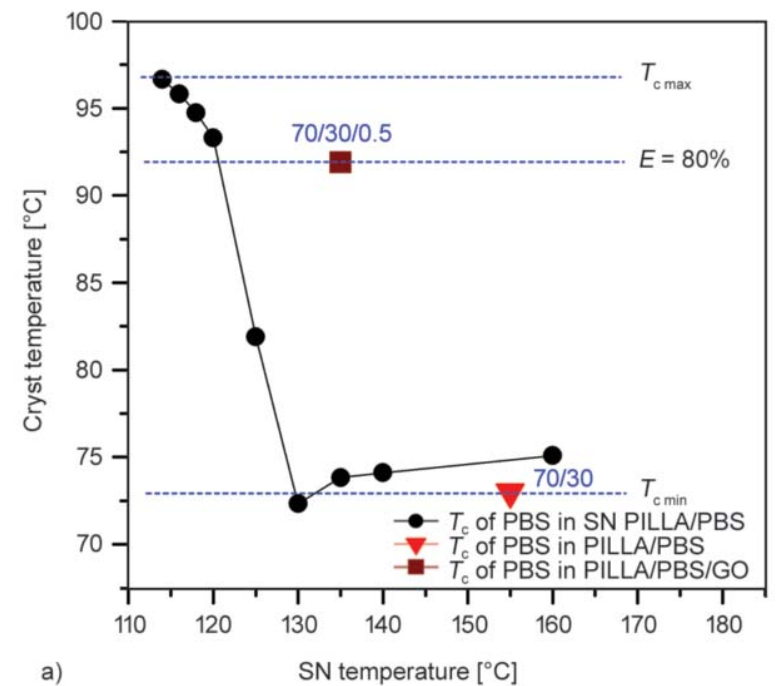

cleation efficiencies higher than $100 \%$ are sometime observed in nanocomposites with high degree of nanofiller dispersion [59]. As such, the proposed preparation method enhances the relatively mild nucleating efficiency of GO to the level of the best known nucleants for poly(butylene succinate), when used at comparable concentration. [60-62].

In Figure $4 \mathrm{~b}$ the nucleating efficiency of $\mathrm{GO}$ on the PLLA matrix is determined by comparison with selfnucleated PLLA. The self-nucleation behaviour of PLLA in neat PLLA/PBS blend is analogous to the one of the PBS component: the crystallization temperature increase by more than $30^{\circ} \mathrm{C}$ for seeding temperatures lower than $175^{\circ} \mathrm{C}$. On the other hand the nucleation effect of $\mathrm{GO}$ nanosheets is much less marked with respect to the one measured for PBS, see Figure $4 \mathrm{a}$. In fact, an increase of crystallization temperature about $5^{\circ} \mathrm{C}$ only with respect to non-selfnucleated melt is observed. This shift correspond to nucleating efficiency of $15 \%$. The differences in nucleating ability of GO towards the two polymers is ascribed to morphology of the blend nanocomposites, as previously discussed. Indeed the majority of graphene oxide are located inside the PBS phase or at the phase boundaries (see Figure 1 and Figure 2). The high nucleation density, naturally occurring in semicrystalline polymers when non-isothermally crystallized at relatively low temperatures, might effectively hide the effect of nucleating agents with low efficiency. In fact, the effect of an enhanced nucleation density on crystallization kinetics can be detected only if the number of extra-nuclei is at least

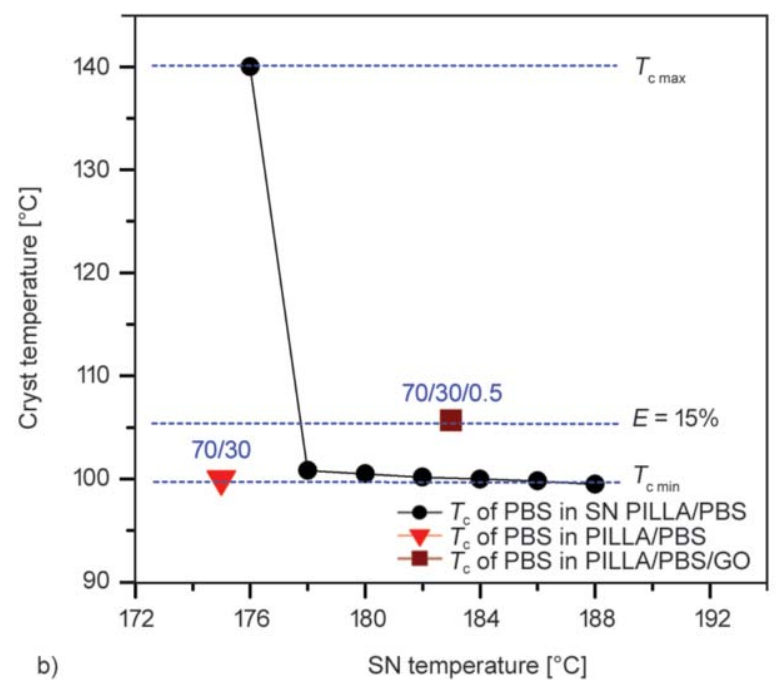

Figure 4. Crystallization temperature of the PBS (a) and PLLA (b) phase in PLLA/PBS neat blend as a function of the selfnucleation (SN) temperature. The data of the non-self-nucleated blend and of a PLLA/PBS/GO nanocomposite are added for comparison (see text) 
comparable to the 'reference' concentration of nuclei of the neat system. Given that, this reference number is lower at higher crystallization temperature; isothermal crystallization experiments at the proper temperature could possibly highlight mild nucleating effects. Therefore, an isothermal crystallization protocol is separately applied to the two polyesters. Examples of typical DSC results are shown in Figure 5 for PBS Figure 5a and PLLA Figure 5b, respectively. Figure 5a shows the comparison between neat PBS and PLLA/PBS/GO with different content of nanofiller. Due to the differences in crystallization kinetics, the neat PLLA/PBS blend could not be probed at similar temperatures. Also, neat PBS needs to be crystallized at $2{ }^{\circ} \mathrm{C}$ higher undercooling with respect to the PLLA/PBS/GO nanocomposites to display a similar kinetics. Yet, crystallization is completed in about 200 seconds for the nanocomposites, while it requires more than 1000 seconds in the neat PBS homopolymer. No effect of GO concentration is observed, indicating that its nucleation activity on PBS saturates already at concentrations of $0.1 \mathrm{wt} \%$ or lower. Thus, a different nucleating effect and saturation concentration of the nanofiller exists, with respect to PBS, confirming the deductions of non-isothermal crystallization experiments. The crystallization of the PLLA phase in PLLA/PBS neat blend and in the blend with $\mathrm{GO}$ nanofiller at $124^{\circ} \mathrm{C}$ is shown as an example in Figure 5b. In this case, a smaller accelerating effect is obtained: the overall crystallization rate, as evaluated form the peak-time, is about three time faster for 0.3 and $0.5 \mathrm{wt} \% \mathrm{GO}$, while it is only slightly faster for the $0.1 \mathrm{wt} \%$.

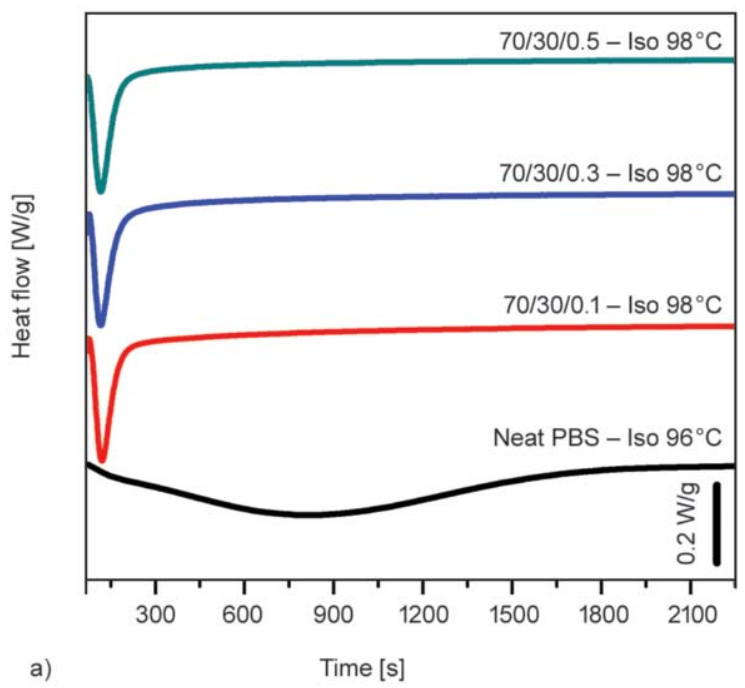

The results of overall crystallization kinetics of the two phases for the pure components, the 70/30 PLLA/PBS blend and the blend/GO nanocomposites are collected in a wider range of undercoolings and shown in Figure 6. The peak time of crystallization is chosen as a representative parameter to describe the overall isothermal crystallization kinetics. In Figure 6a the transformation of the PBS phase is considered. For all samples, the expected increasing trend with increasing crystallization temperature is observed, with an increase of the crystallization time of about one order of magnitude by decreasing the undercooling by less than $10^{\circ} \mathrm{C}$. The nucleating effect of GO with respect to pure PBS and PLLA/PBS neat blend can be appreciated by considering the shift in undercooling required to obtain a comparable crystallization kinetics.

Indeed, the nanocomposites possess a kinetics comparable to that of the pure PBS at much lower undercoolings: the shift in temperature is around $10^{\circ} \mathrm{C}$. This difference is even more important if one would consider the PLLA/PBS blend. Unfortunately, the slow crystallization kinetics of the neat blend prevents the direct measurement of latent heat evolution in isothermal conditions. The crystallization kinetics is practically independent of GO concentration, although small differences are observed between 0.1 and the higher concentrations at crystallization temperatures above $102{ }^{\circ} \mathrm{C}$.

Similarly, the crystallization kinetics data of the PLLA phase in the neat polymer, blend and nanocomposites are compared in Figure 6b. It can be noted that, while the nucleating effect of GO was

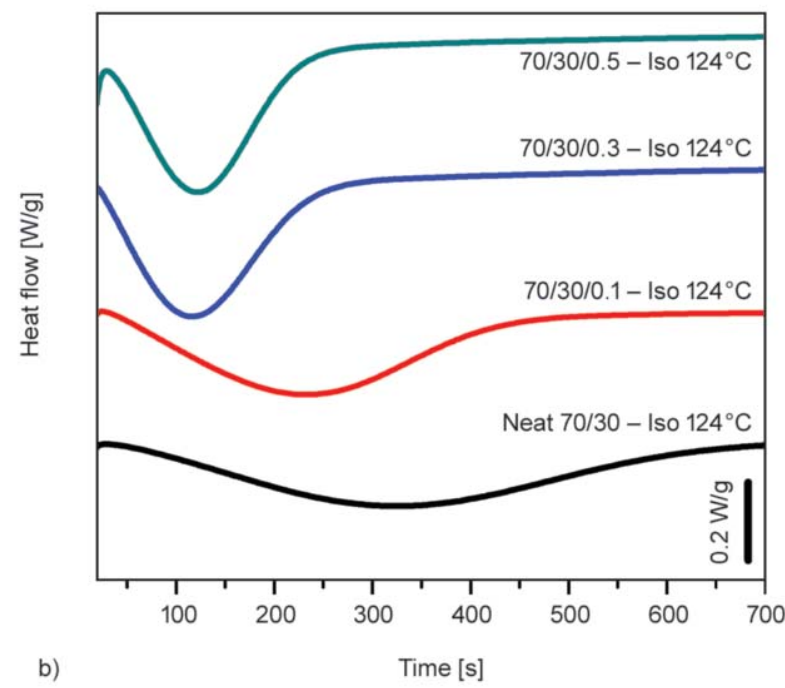

Figure 5. Heat flow as a function of time during the crystallization of PBS (a) and PLLA (b) phase in PLLA/PBS blend and PLLA/PBS/GO blend nanocomposites 

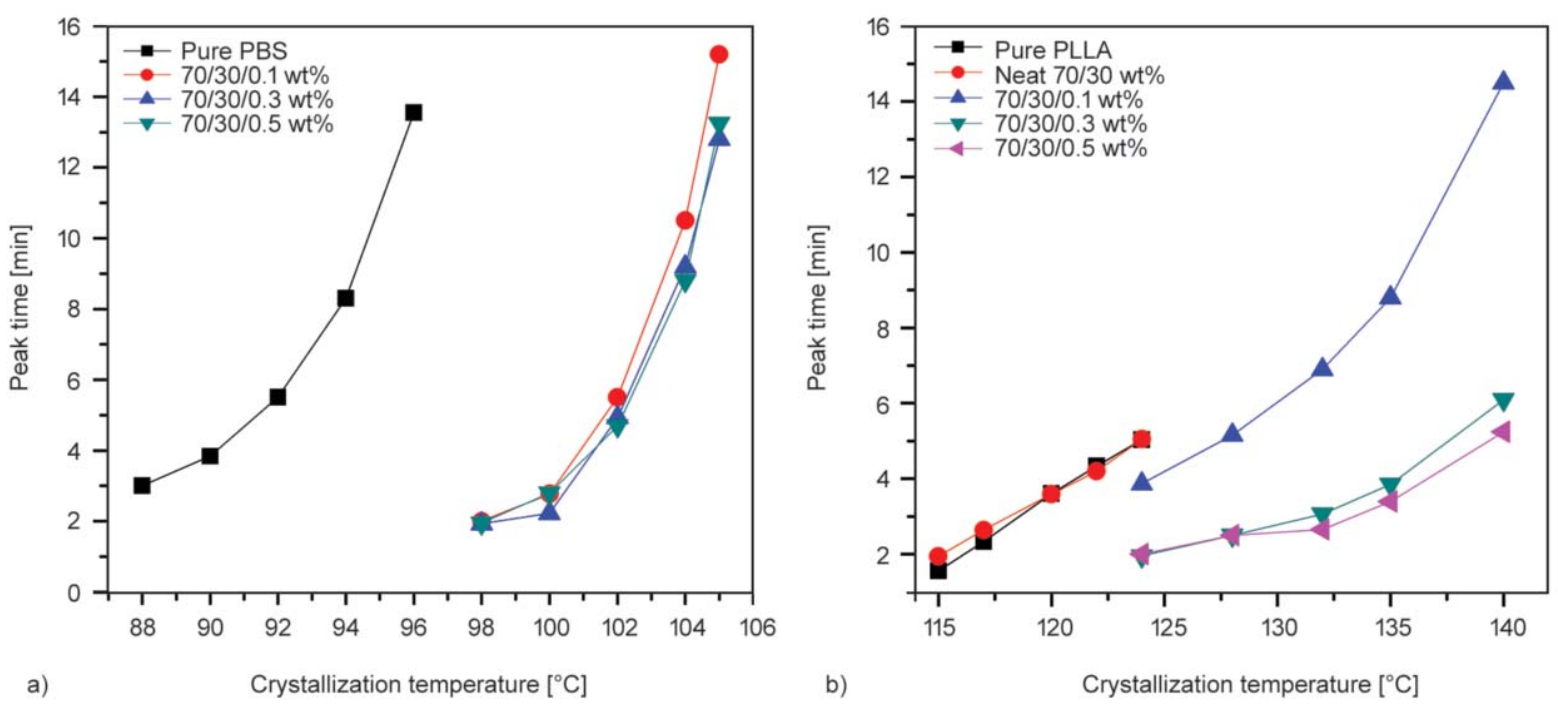

Figure 6. Crystallization peak time as a function of crystallization temperature for PBS (a) and PLLA (b) phase in PLLA/PBS blend and PLLA/PBS/GO blend nanocomposites

almost unnoticed in non-isothermal crystallization, by performing isothermal measurement at relatively high temperature it clearly shows up. In fact, adding $0.3-0.5 \mathrm{wt} \%$ of $\mathrm{GO}$ corresponds to a gain of $15^{\circ} \mathrm{C}$ in undercoolings in terms of crystallization kinetics. In other words, the nanocomposites should be crystallized at much higher temperatures to have a rate of crystallization similar to that of PLLA/PBS neat blend. Contrary to PBS, a concentration effect is found for the nucleating efficiency of PLLA: the efficiency increases going from 0.1 to $0.3 \mathrm{wt} \%$, and seems to saturate at this concentration. Incidentally, the nucleation effect of PBS molten droplet on PLLA crystallization, which was deduced from non-isothermal crystallization experiments (see Figure 3a) is not confirmed in isothermal experiment. We recall that surfaces with different nucleating ability become effective at different temperatures, the lower the efficiency of the nucleating surface, the higher the required undercooling to observe this effect. Therefore, the lack of nucleating effect of molten PBS on PLLA at high temperature might indicate a very low activity of this heterogeneity, which becomes effective only at much lower crystallization temperatures, such as those reached in non-isothermal crystallization.

\section{Conclusions}

The interest in using graphene oxide to improve the properties of polymer nanocomposites is recently rising. Similarly, graphene, graphene oxide and other nanoparticles are frequently used to modify the interface between immiscible polymer blends (twophases, three components systems). In this work, the

relation between the obtained multiphase morphology of PLLA/PBS/GO blend nanocomposites was thoroughly investigated, with particular attention to the distribution of GO in the two polymers and at their interfaces. The morphological information obtained with Scanning and Transmission Electron Microscopy is the basis to understand the role of GO in the nucleation process of the two crystalline blend components. GO improves the adhesion between the two polymers, and have nucleation ability towards both PBS and PLLA. In particular, a remarkable effect is found on the minor PBS dispersed phase. The obtained results show a promising route to tune the crystallization and thus end-use properties of biobased polymer blends, an issue of technological importance for the development of novel 'green' materials.

\section{References}

[1] Wang R., Wang S., Zhang Y., Wan C., Ma P.: Toughening modification of PLLA/PBS blends via in situ compatibilization. Polymer Engineering and Science, 49, 26-33 (2009).

https://doi.org/10.1002/pen.21210

[2] Chen G-X., Kim H-S., Kim E-S., Yoon J-S.: Compatibilization-like effect of reactive organoclay on the poly(L-lactide)/poly(butylene succinate) blends. Polymer, 46, 11829-11836 (2005).

https://doi.org/10.1016/j.polymer.2005.10.056

[3] Elwathig H., You W., He J., Yu M.: Dynamic mechanical properties and thermal stability of poly(lactic acid) and poly(butylene succinate) blends composites. Journal of Fiber Bioengineering and Informatics, 6, 85-94 (2013).

https://doi.org/10.3993/jfbi03201308 
[4] Yokohara T., Yamaguchi M.: Structure and properties for biomass-based polyester blends of PLA and PBS. European Polymer Journal, 44, 677-685 (2008). https://doi.org/10.1016/j.eurpolymj.2008.01.008

[5] Nerkar M., Ramsay J. A., Ramsay B. A., Vasileiou A. A., Kontopoulou M.: Improvements in the melt and solid-state properties of poly(lactic acid), poly-3-hydroxyoctanoate and their blends through reactive modification. Polymer, 64, 51-61 (2015).

https://doi.org/10.1016/j.polymer.2015.03.015

[6] Persenaire O., Quintana R., Lemmouchi Y., Sampson J., Martin S., Bonnaud L., Dubois P.: Reactive compatibilization of poly(L-lactide)/poly(butylene succinate) blends through polyester maleation: From materials to properties. Polymer International, 63, 1724-1731 (2014). https://doi.org/10.1002/pi.4700

[7] Anderson K. S., Schreck K. M., Hillmyer M. A.: Toughening polylactide. Polymer Reviews, 48, 85-108 (2008). https://doi.org/10.1080/15583720701834216

[8] Homklin R., Hongsriphan N.: Mechanical and thermal properties of PLA/PBS co-continuous blends adding nucleating agent. Energy Procedia, 34, 871-879 (2013). https://doi.org/10.1016/j.egypro.2013.06.824

[9] Robeson L.: Historical perspective of advances in the science and technology of polymer blends. Polymers, 6, 1251-1265 (2014). https://doi.org/10.3390/polym6051251

[10] Paul D. R., Barlow J. W.: A brief review of polymer blend technology. in 'Advances in chemistry: Multiphase polymers' (Ed.: Cooper S. L.) American Chemical Society, Washington, Vol 17, 315-335 (1979). https://doi.org/10.1021/ba-1979-0176.ch017

[11] Buasri A., Buranasing G., Piemjaiswang R., Yousatit S., Loryuenyong V.: Effect of titanium dioxide nanoparticles on mechanical and thermal properties of poly(lactic acid) and poly(butylene succinate) blends. Advances in Science and Technology, 96, 33-38 (2014). https://doi.org/10.4028/www.scientific.net/AST.96.33

[12] Mofokeng J. P., Luyt A. S.: Dynamic mechanical properties of PLA/PHBV, PLA/PCL, PHBV/PCL blends and their nanocomposites with $\mathrm{TiO}_{2}$ as nanofiller. Thermochimica Acta, 613, 41-53 (2015). https://doi.org/10.1016/j.tca.2015.05.019

[13] Monticelli O., Calabrese M., Gardella L., Fina A., Gioffredi E.: Silsesquioxanes: Novel compatibilizing agents for tuning the microstructure and properties of PLA/PCL immiscible blends. European Polymer Journal, 58 6978 (2014).

https://doi.org/10.1016/j.eurpolymj.2014.06.021

[14] Yang J., Feng C., Dai J., Zhang N., Huang T., Wang Y.: Compatibilization of immiscible nylon 6/poly(vinylidene fluoride) blends using graphene oxides. Polymer International, 62, 1085-1093 (2013).

https://doi.org/10.1002/pi.4396

[15] Cao Y., Zhang J., Feng J., Wu P.: Compatibilization of immiscible polymer blends using graphene oxide sheets. American Chemical Society Nano, 5, 5920-5927 (2011). https://doi.org/10.1021/nn201717a
[16] Ku K. H., Yang H., Jang S. G., Bang J., Kim B. J.: Tailoring block copolymer and polymer blend morphology using nanoparticle surfactants. Journal of Polymer Science Part A: Polymer Chemistry, 54, 228-237 (2016). https://doi.org/10.1002/pola.27899

[17] Dil E. J., Favis B. D.: Localization of micro- and nanosilica particles in heterophase poly(lactic acid)/poly (butylene adipate-co-terephthalate) blends. Polymer, 76, 295-306 (2015). https://doi.org/10.1016/j.polymer.2015.08.046

[18] Ock H. G., Kim D. H., Ahn K. H., Lee S. J., Maia J. M.: Effect of organoclay as a compatibilizer in poly(lactic acid) and natural rubber blends. European Polymer Journal, 76, 216-227 (2016). https://doi.org/10.1016/j.eurpolymj.2016.01.042

[19] Vrsaljko D., Macut D., Kovačević V.: Potential role of nanofillers as compatibilizers in immiscible PLA/LDPE blends. Journal of Applied Polymer Science, 132, 41414/1-41414/14 (2015).

https://doi.org/10.1002/app.41414

[20] Arrieta M. P., Fortunati E., Dominici F., López J., Kenny J. M.: Bionanocomposite films based on plasticized PLA-PHB/cellulose nanocrystal blends. Carbohydrate Polymers, 121, 265-275 (2015).

https://doi.org/10.1016/j.carbpol.2014.12.056

[21] Noori F. T. M., Ali N. A.: Study the mechanical and thermal properties of biodegradable polylactic acid/poly ethylene glycol nanocomposites. International Journal of Application or Innovation in Engineering and Management, 3, 459-464 (2014).

[22] Shibata M., Inoue Y., Miyoshi M.: Mechanical properties, morphology, and crystallization behavior of blends of poly(L-lactide) with poly(butylene succinate-co-Llactate) and poly(butylene succinate). Polymer, 47, 35573564 (2006).

https://doi.org/10.1016/j.polymer.2006.03.065

[23] Zhang X., Zhang Y.: Reinforcement effect of poly(butylene succinate) (PBS)-grafted cellulose nanocrystal on toughened PBS/polylactic acid blends. Carbohydrate Polymers, 140, 374-382 (2016). https://doi.org/10.1016/j.carbpol.2015.12.073

[24] Luzi F., Fortunati E., Jiménez A., Puglia D., Pezzolla D., Gigliotti G., Kenny J. M., Chiralt A., Torre L.: Production and characterization of PLA/PBS biodegradable blends reinforced with cellulose nanocrystals extracted from hemp fibres. Industrial Crops and Products, 93, 276-289 (2016).

https://doi.org/10.1016/j.indcrop.2016.01.045

[25] Deng Y., Thomas N. L.: Blending poly(butylene succinate) with poly(lactic acid): Ductility and phase inversion effects. European Polymer Journal, 71, 534-546 (2015). https://doi.org/10.1016/j.eurpolymj.2015.08.029

[26] Kawamoto N., Sakai A., Horikoshi T., Urushihara T., Tobita E.: Physical and mechanical properties of poly(L-lactic acid) nucleated by dibenzoylhydrazide compound. Journal of Applied Polymer Science, 103, 244-250 (2007). https://dx.doi.org/10.1002/app.25185 
[27] Ye S., Cao Y., Feng J., Wu P.: Temperature-dependent compatibilizing effect of graphene oxide as a compatibilizer for immiscible polymer blends. RSC Advances, 3, 7987-7995 (2013).

https://doi.org/10.1039/C3RA40253C

[28] Cao Y., Feng J., Wu P.: Polypropylene-grafted graphene oxide sheets as multifunctional compatibilizers for polyolefin-based polymer blends. Journal of Materials Chemistry, 22, 14997-15005 (2012).

https://doi.org/10.1039/C2JM31477K

[29] Tong Y., Lin Y., Wang S., Song M.: A study of crystallisation of poly (ethylene oxide) and polypropylene on graphene surface. Polymer, 73, 52-61 (2015).

https://doi.org/10.1016/j.polymer.2015.07.025

[30] Yang S., Li Y., Liang Y-Y., Wang W-J., Luo Y., Xu J-Z., Li Z-M.: Graphene oxide induced isotactic polypropylene crystallization: Role of structural reduction. RSC Advances, 6, 23930-23941 (2016).

https://doi.org/10.1039/C5RA26902D

[31] Xu J-Z., Liang Y-Y., Huang H-D., Zhong G-J., Lei J., Chen C., Li Z-M.: Isothermal and nonisothermal crystallization of isotactic polypropylene/graphene oxide nanosheet nanocomposites. Journal of Polymer Research, 19, 9975-9982 (2012).

https://doi.org/10.1007/s10965-012-9975-5

[32] He L., Cui B., Jia N., Sun J., Xia G., Zhang H., Song R.: Enhanced $\beta$ crystalline phase in poly(vinylidene fluoride) via the incorporation of graphene oxide sheets assisted by supercritical $\mathrm{CO}_{2}$ treatment. Journal of Macromolecular Science Part B: Physics, 55, 503-517 (2016). https://doi.org/10.1080/00222348.2016.1170253

[33] Tong J., Huang H. X., Wu M.: Structure and properties of pvdf/go nanocomposites prepared by water-assisted mixing extrusion. In 'ANTEC Plastics Technology Conference, Indianapolis, USA' 488-492 (2016).

[34] Hu Y-C., Hsu W-L., Wang Y-T., Ho C-T., Chang-Z.: Enhance the pyroelectricity of polyvinylidene fluoride by graphene-oxide doping. Sensors, 14, 6877-6890 (2014). https://doi.org/10.3390/s140406877

[35] Wang B., Li Y., Weng G., Jiang Z., Chen P., Wang Z., Gu Q.: Reduced graphene oxide enhances the crystallization and orientation of poly( $\varepsilon$-caprolactone). Composites Science and Technology, 96, 63-70 (2014). https://doi.org/10.1016/j.compscitech.2014.03.012

[36] Zhao L., Liu X., Zhang R., He H., Jin T., Zhang J.: Unique morphology in polylactide/graphene oxide nanocomposites. Journal of Macromolecular Science Part B: Physics, 54, 45-57 (2015). https://doi.org/10.1080/00222348.2014.984574

[37] Li Y-D., Li H., Du A-K., Wang M., Zeng J-B.: Morphology and isothermal crystallization of graphene oxide reinforced biodegradable poly(butylene succinate). Polymer Testing, 59, 1-9 (2017).

https://doi.org/10.1016/j.polymertesting.2017.01.014

[38] Paredes J. I., Villar-Rodil S., Martinez-Alonso A., Tascón J. M. D.: Graphene oxide dispersions in organic solvents. Langmuir, 24, 10560-10564 (2008).

https://doi.org/10.1021/la801744a
[39] Kawai T., Rahman N., Matsuba G., Nishida K., Kanaya T., Nakano M., Okamoto H., Kawada J., Usuki A., Honma N., Nakajima K., Matsuda M.: Crystallization and melting behavior of poly (L-lactic acid). Macromolecules, 40, 9463-9469 (2007).

https://doi.org/10.1021/ma070082c

[40] Androsch R., Schick C., Di Lorenzo M. L.: Melting of conformationally disordered crystals ( $\alpha^{\prime}$-phase) of poly (L-lactic acid). Macromolecular Chemistry and Physics, 215, 1134-1139 (2014). https://doi.org/10.1002/macp.201400126

[41] Santana O. O., Müller A. J.: Homogeneous nucleation of the dispersed crystallisable component of immiscible polymer blends. Polymer Bulletin, 32, 471-477 (1994). https://doi.org/10.1007/bf00587890

[42] Wu D., Yuan L., Laredo E., Zhang M., Zhou W.: Interfacial properties, viscoelasticity, and thermal behaviors of poly(butylene succinate)/polylactide blend. Industrial and Engineering Chemistry Research, 51, 2290-2298 (2012). https://doi.org/10.1021/ie2022288

[43] Mitra M. K., Muthukumar M.: Theory of spinodal decomposition assisted crystallization in binary mixtures. Journal of Chemical Physics, 132, 184908/1-184908/6 (2010).

https://doi.org/10.1063/1.3425774

[44] Shi W., Chen F., Zhang Y., Han C. C.: Viscoelastic phase separation and interface assisted crystallization in a highly immiscible iPP/PMMA blend. ACS Macro Letters, 1, 1086-1089 (2012). https://doi.org/10.1021/mz300312e

[45] Wang X. W., Zhang C-A., Wang P. L., Zhao J., Zhang W., Ji J. H., Hua K., Zhou J., Yang X. B., Li X. P.: Enhanced performance of biodegradable poly(butylene succinate)/graphene oxide nanocomposites via in situ polymerization. Langmuir, 28, 7091-7095 (2012). https://doi.org/10.1021/la204894h

[46] Wan C., Chen B.: Reinforcement of biodegradable poly (butylene succinate) with low loadings of graphene oxide. Journal of Applied Polymer Science, 127, 5094-5099 (2013).

https://doi.org/10.1002/app.38136

[47] Geng L-H., Peng X-F., Jing X., Li L-W., Huang A., Xu B-P., Chen B-Y., Mi H-Y.: Investigation of poly(L-lactic acid)/graphene oxide composites crystallization and nanopore foaming behaviors via supercritical carbon dioxide low temperature foaming. Journal of Materials Research, 31, 348-359 (2016).

https://doi.org/10.1557/jmr.2016.13

[48] Chen Y., Yao X., Gu Q., Pan Z.: Non-isothermal crystallization kinetics of poly (lactic acid)/graphene nanocomposites. Journal of Polymer Engineering, 33, 163-171 (2013).

https://doi.org/10.1515/polyeng-2012-0124 
[49] Wu D., Cheng Y., Feng S., Yao Z., Zhang M.: Crystallization behavior of polylactide/graphene composites. Industrial and Engineering Chemistry Research, 52, 67316739 (2013).

https://doi.org/10.1021/ie4004199

[50] Yoo E. S., Im S. S.: Melting behavior of poly(butylene succinate) during heating scan by DSC. Journal of Polymer Science Part B: Polymer Physics, 37, 1357-1366 (1999).

https://doi.org/10.1002/(SICI)10990488(19990701)37:13<1357::AID-POLB2>3.0.CO;2-Q

[51] Wang X., Zhou J., Li L.: Multiple melting behavior of poly(butylene succinate). European Polymer Journal, 43, 3163-3170 (2007).

https://doi.org/10.1016/j.eurpolymj.2007.05.013

[52] Yasuniwa M., Satou T.: Multiple melting behavior of poly(butylene succinate). I. Thermal analysis of meltcrystallized samples. Journal of Polymer Science Part B: Polymer Physics, 40, 2411-2420 (2002). https://doi.org/10.1002/polb.10298

[53] Yasuniwa M., Tsubakihara S., Satou T., Iura K.: Multiple melting behavior of poly(butylene succinate). II. Thermal analysis of isothermal crystallization and melting process. Journal of Polymer Science Part B: Polymer Physics, 43, 2039-2047 (2005).

https://doi.org/10.1002/polb.20499

[54] Fillon B., Thierry A., Lotz B., Wittmann J. C.: Efficiency scale for polymer nucleating agents. Journal of Thermal Analysis, 42, 721-731 (1994). https://doi.org/10.1007/BF02546745

[55] Sabino M. A., Ronca G., Müller A. J.: Heterogeneous nucleation and self-nucleation of poly(p-dioxanone). Journal of Materials Science, 35, 5071-5084 (2000). https://doi.org/10.1023/A:1004831731756

[56] Yin H-Y., Wei X-F., Bao R-Y., Dong Q-X., Liu Z-Y., Yang W., Xie B-H., Yang M-B.: High-melting-point crystals of poly(L-lactic acid) (PLLA): the most efficient nucleating agent to enhance the crystallization of PLLA. CrystEngComm, 17, 2310-2320 (2015).

https://doi.org/10.1039/C4CE02497D
[57] Schmidt S. C., Hillmyer M. A.: Polylactide stereocomplex crystallites as nucleating agents for isotactic polylactide. Journal of Polymer Science Part B: Polymer Physics, 39, 300-313 (2001).

https://doi.org/10.1002/10990488(20010201)39:3<300::AID-POLB1002>3.0.CO;2-M

[58] Song P., Wei Z., Liang J., Chen G., Zhang W.: Crystallization behavior and nucleation analysis of poly(L-lactic acid) with a multiamide nucleating agent. Polymer Engineering and Science, 52, 1058-1068 (2012). https://doi.org/10.1002/pen.22172

[59] Müller A. J., Arnal M. L., Trujillo M., Lorenzo A. T.: Super-nucleation in nanocomposites and confinement effects on the crystallizable components within block copolymers, miktoarm star copolymers and nanocomposites. European Polymer Journal, 47, 614-629 (2011). https://doi.org/10.1016/j.eurpolymj.2010.09.027

[60] Filizgok S., Kodal M., Ozkoc G.: Non-isothermal crystallization kinetics and dynamic mechanical properties of poly(butylene succinate) nanocomposites with different type of carbonaceous nanoparticles. Polymer Composites, in press (2017). https://doi.org/10.1002/pc.24261

[61] Tang Y-R., Lin D-W., Gao Y., Xu J., Guo B-H.: Prominent nucleating effect of finely dispersed hydroxylfunctional hexagonal boron nitride on biodegradable poly(butylene succinate). Industrial and Engineering Chemistry Research, 53, 4689-4696 (2014). https://doi.org/10.1021/ie403915j

[62] Ye H-M., Tang Y-R., Xu J., Guo B-H.: Role of poly (butylene fumarate) on crystallization behavior of poly (butylene succinate). Industrial and Engineering Chemistry Research, 52, 10682-10689 (2013). https://doi.org/10.1021/ie4010018 